\title{
Research on China's Public Policy Discipline Construction Based on National Strategic Perspective
}

\author{
Xiaoyan Liu \\ School of Public Administration, Sichuan University, Chengdu, 610064, China \\ 20175260@qq.com
}

Keywords: national strategy; public policy; discipline construction.

\begin{abstract}
The interaction between national strategy and public policy discipline is close. The national strategy guides, leads and standardizes China's discipline construction of public policy, China's discipline construction of public policy reacts and supports the national strategy, and they are both influenced by space-time situation and human factors. There are two major problems in China's discipline construction of public policy. The first is that the national strategy restricts the discipline construction of public policy and the second is that the discipline construction of public policy lacks support for the national strategy. The solutions of the problems are strengthening the positive guiding role of China's national strategy for the discipline construction of public policy and enhancing the support role of China's public policy discipline for the national strategy.
\end{abstract}

\section{Introduction}

The term "policy" is evolved from "politic", which is a strategic approach mainly in order to achieve a certain political purpose. [1] It can be seen from the results of policy researches that scholars' policy definitions and interpretations are not the same. For example, scholar Lasswell and Kaplan define public policy as a large plan with goals, values and strategy; and scholar Robert Eyestone thinks that public policy is the interaction between government agencies and their surroundings from an interactive perspective; scholar David Easton regards public policy as authoritative distribution for value of whole society; Chinese scholar Chen Zhenming thinks that public policy is political action taken or specified code of conduct that country (government) the ruling party or other political groups in order to achieve a certain social, political, economic and cultural goals in a specific period, and it is the general name of a series of strategies, decrees, measures, methods, methods, regulations and so on. [2] It can be seen that public policy is the strategy, measure, operative norm and guideline taken by the State in order to achieve specific purposes.

Although public policy has existed since the city-state was established, public policy did not become a discipline until the middle of the last century. The discipline is the unity of comprehensiveness and interdisciplinary characteristics, the unity of theory and practice, the unity of political sensitivity and publicity of value orientation, the unity of science and artistry, and the unity of openness and regionalism. [3] Discipline construction is a comprehensive, systematic and dynamic project, including scientific research and construction, personnel training system construction, discipline team construction, discipline base construction, academic environment construction, academic exchange and other contents, elements or links. [4] The discipline construction of public policy is a systematic activity which is under the guidance of certain rationality, based on public policy knowledge system, cultivating public policy talents as the core, by strengthening the hardware and software investment and carrying out scientific and reasonable teaching and research activities, in order to promote the sustainable development of academic system and enhance the service social capacity.

Domestic and foreign scholars research the discipline construction problems of public policy mostly from the discipline construction of public policy itself, but ignore that the discipline construction of public policy cannot be separated from the country's support, and must be influenced by national development level and strategic direction. Therefore, it is necessary to explore the 
discipline construction problem of public policy from the perspective of national strategy and provide a new reference path.

\section{Relationship between National Strategy and Public Policy Discipline}

The term strategy comes from the Greek language, whose meaning is generalship. It originates from military practice, and later extends from military strategy to non-strategic areas. National strategy is the application of strategic thinking in the field of national governance. Scholar Ingrid Bonn thinks that strategic thinking is the way to solve strategic problems, which is composed of rational and convergent paths, and creative and divergent processes, including a series of key factors such as system thinking, creativity and vision. [5] In terms of national strategy, the definition of scholar Bo Guili's is relatively representative. He thinks that the national strategy is the overall strategy of maintaining and enhancing national interests, achieving national goals and comprehensive development, and rational allocation and effective use of national power. [6]

China's national strategy inter-depends and mutually influences the discipline construction of public policy. The national strategy guides, leads and standardizes China's discipline construction of public policy, China's discipline construction of public policy reacts and supports national strategy, and both are influenced by time-space situation and human factors.

First, China's national strategy guides and standardizes the discipline construction of public policy. China's discipline construction of public policy is based on the principle of Socialism and MarxismLeninism, and it is carried out under the state administration of relevant rules on the discipline construction and development. On the one hand, the public policy discipline, as one of many disciplines, is within the relevant norms of the country. The construction and development of the discipline needs to comply with the state relevant regulations; on the other hand, the construction and development of the discipline requires a lot of manpower, financial and material resources which are inseparable from the country's support.

Second, China's discipline construction of public policy reacts and supports the national strategy. One of the contents of the discipline construction of public policy is public policy research which includes the research of existing policies and the prediction research of future policy. Through the research of existing policies and proposing suggestions, it is possible to promote the decomposition and refinement of national strategies, assess the implementation process and effectiveness, and timely improve existing policies. In addition, through the rich theoretical research and learning at home and abroad, combined with Chinese practice, the Party and the government are easier to master China's national conditions and international situation, so as to provide a predictive reference for the future strategic development of the country.

Third, China's national strategy and the discipline construction of public policy will be influenced by space-time situation and human factors. Both the national strategy and the discipline construction of public policy are carried out by people in a certain time and space background, so the national strategy and discipline construction of public policy are closely linked to objective social environment and the people involved.

\section{Dilemma of China's Discipline Construction of Public Policy}

China's discipline construction of public policy has achieved initial construction results, however, from the perspective of national strategy, there are still two problems in the discipline construction of public policy, that is, the national strategy restricts the discipline construction of public policy, and China's discipline construction of public policy lacks support for the national strategy.

First, China's national strategy plays restrictive role for the discipline construction of public policy. On the one hand, the administrative color of China's discipline construction of public policy is strong. In our country, the Party plays a guiding and leading role in national and social management and development, and the concept of discipline construction of public policy should be consistent with the Party's ruling idea. The establishments of public policy discipline, discipline planning, academic research funds support, and even academic researcher's personal career development are basically 
influenced by the relevant national policy and even leaders' individual will. On the other hand, the discipline construction of public policy favors one more than another. Scholars' researches tend to follow the hot issues raised by the Party and government, which have strong political tendencies. Some public policy problems are bound to be research focus, and some public policy problems are marginalized.

Second, China's discipline construction of public policy lacks support for the national strategy. Through the feedback of public policy researches, China's national strategy can be decomposed and refined scientifically and reasonably, and the implementation efficiency of policy is improved to ensure the achievement of national strategic development goals. Public policy requires the guidance of national strategies, but it should not be an accessory of national strategy. It should play its prediction and think tank role. However, from the discipline construction of China's public policy, there are several problems. First, the discipline construction is anxious to achieve quick success and get instant benefits. Some universities neglect their own foundation and conditions in the subject construction, and blindly pursue high starting point and high level in the target positioning; or onesided pursue the scale and quantity expansion, emphasize the output of scientific research at the expense of teaching quality, which is not conducive to the long-term development of China's public policy and will inevitably lead the discipline construction astray. Second, there are some misunderstandings in the cognition of discipline construction, for example: the discipline constructions are regarded as equivalent to professional construction or curriculum construction; the level of academic leaders is regarded as equal to the level of discipline development, and do not attach importance to or neglect the development of academic leaders and teams; [7] Third, the localized academic construction is not confident. The strategic thought in ancient China, policy thought tradition of Marxism, theory and practice of Mao Zedong's are precious wealth to construct scientific system of public policy with Chinese characteristics, but there are less combing and theory distillation for those precious wealth in the research of public policy in our country. Chinese scholars seem to prefer the introduction and application of Western public policy theory to reflect its contribution importance to this disciplinary academic research, so that it is difficult for Chinese public policy research to form their own schools and sects, and perfect or even subvert the existing public policy theory system. Finally, there is insufficient positive interaction between theoretical research and practice. Due to the lack of westernization of research theory and the research methods, the guiding significance of the theoretical research of public policy in our country is limited to a certain extent. And meanwhile, various new affairs and problems boom in the social transition period, and the complete import and export mechanism for effectively solving this process lack.

\section{Paths of China's Discipline Construction of Public Policy}

China's discipline construction of public policy is reflected from the perspective of national strategy. There are two major problems in China's discipline construction of public policy, that is, the national strategy restricts the discipline construction of public policy and the discipline construction of public policy lacks support for the national strategy. The solutions of these problems are as followings.

The first is to strengthen the positive guiding role of China's national strategy of the discipline construction of public policy. National strategy is the top design and the overall significance and the country's various undertaking should be carried out under the framework of national strategy, ensuring the formation of concerted effort to achieve strategic objectives. First of all, it should be ensured that China's discipline construction of public policy is carried out under the framework of national strategy, in order to achieve the goal of discipline construction for national construction. Secondly, monitoring the discipline construction quality of public policy, preventing the occurrence of academic bad behaviors, and minimizing the waste in discipline construction caused by repeated behaviors to ensure that the discipline construction of public policy is helpful to support national development. And finally, the independence of public policy research should be protected. Although the discipline construction of public policy should incline resources to key public policy areas under 
the guidance of the national strategy, scholars should be guided and encouraged to carry out research objects that their own concern by fair, open and just work mechanism.

The second is to construct localized theory of China's public policy. Because there is inapplicable phenomenon when scholars analyze and solve the problems of China's public policy with western public policy theory, and some scholars have begun to rethink differentiation problems of Chinese and Western public policy theories, the localized problems of public policy theory have attracted the attention of scholars. From present situation of the academic research, scholars building localized theory of China's public policy should work hard from the following three aspects: firstly, theoretical system of public policy with Chinese characteristics is built through the "from theory to theory" and " from practice to theory" construction ways, and provides reference for other developing countries. Secondly, philosophical thinking of China's public policy research are promoted. The development of policy science is very closely related to philosophy, as American famous policy scholar George J.McCall and George H.Weber said: "philosophy as a mother science, which has a significant impact on the core of policy science. Its contribution to policy science is more profound and meaningful than the natural and social sciences. "[8] Finally, the development of China's public policy schools and sect prosper. Good academic ecology in the localization process of public policy, the development of China's public policy schools and sect prosper, and the improved discipline systems of public policy create a good growing soil for the discipline construction.

The third is to strengthen research team construction of public policy. The first is to attract highlevel domestic and foreign scholars to join the discipline research team of public policy and the overall quality of the team are enhanced in this way. The second is to increase the training strengthen of existing researchers by encouraging and supporting researchers to participate in teacher training classes or engage in advanced studies to domestic and foreign colleges and universities. The third is to pay attention to the combination of theory and practice. Through the cooperation of universities the government, other research institutions and social organizations, etc. researchers are provided with opportunities to contact with public policy practices. And finally, exchange platforms of China's public policy research are improved. Through the establishment of public policy research authoritative journals, organization of the same disciplines and interdisciplinary exchange seminars and other ways, communication platforms are built to promote the scholars' exchanges and interdisciplinary collision, and stimulate scholars' innovative thinking of public policy research.

The fourth is to improve the self-request of research participants of China's public policy. The research participants of public policy mainly include scholars and students. Scholars as the mainstay of public policy research in our country must be academic self-confidence, and be committed to the improvement and development of public policy disciplines, and the forward-looking to consider the discipline to promote the possibility of human social progress on the basis of compiling the basic theory, research paradigm and research method of subject academic research. For the students of public policy, the foundation of theoretical knowledge and research ability should be consolidated during the students' period, and it is necessary to have the innovative spirit and courage to criticize the existing theories so as to explore the possibility of theory renewal and creation of theories.

\section{Summary}

The relationship between China's national strategy and the discipline construction of public policy is mainly embodied in the followings. The national strategy guides, leads and standardizes China's discipline construction of public policy, China's discipline construction of public policy reacts and supports national strategy, and both of them are influenced by time-space situation and human factors. From the perspective of national strategy, there are two problems in the discipline construction of public policy in our country: the first is that the restrictive role of China's national strategic for the discipline construction of public policy, which is mainly embodied in the strong administrative color of the discipline construction of public policy and the discipline construction of public policy favors one more than another; the second is the lack of support of the discipline construction of public policy in our country, which is mainly embodied in the discipline construction seeking quick success and instant benefits, the misunderstandings in the cognition of discipline construction, and lacked 
confidence in localized academic construction and the less positive interactions between theoretical research and practice. In order to solve these problems, on the one hand, the positive guiding role of China's national strategic for the discipline construction of public policy should be strengthened by bringing the discipline construction of public policy into the national strategic framework, strengthening the country's control of discipline construction of public policy, ensuring the independence of public policy research and so on. On the other hand, the support role of China's public policy disciplines for the national strategy should be enhanced by the establishment of localized theory research of China's public policy, the research team construction of public policy and the improved self-request of public policy research participants and so on.

\section{References}

[1]. Sun Guohua, Chinese Law Dictionary • Jurisprudence Volume.China Procuratorate Press, 1997,p. 506.

[2]. Chen Zhenming. Introduction to public policy analysis. Renmin University of China Press, 2015,p. 21.

[3]. Yuan Mingxu. Exploration on the Innovation Path of Teaching Mode Based on the Characteristics of Public Policy Discipline. Journal of Wenshan University,Vol. 28 (2015) No. 1, p. 99-103.

[4]. Guo Xiaocong, Xiao Shengfu.The Dilemma and Outlet of the Chinese Public Administration Disciplinary Construction. Journal of Renmin University of China, (2006) No. 6, p. 147-152.

[5]. Ingrid Bonn. Improving strategic thinking- a multilevel approach, Leadership\& Organization Development Journal, Vol. 26 (2005)No. 5, p. 336-354.

[6]. Bo Guili. On Scientific Connotation of National Strategy. Chinese Public Administration, (2015) No. 7, p. 70-75.

[7]. Chen Zhenming. Seek a new breakthrough of policy science development- Review and Prospect of China's Public Policy Research for Thirty Years. Chinese Public Administration, (2012) No. 4, p. 12-15.

[8]. Stuart S. Nagel. Policy Research Encyclopedia.Scientific and Technical Documentation Press, 1989,p. 163. 